\title{
Research on the Protection Strategy of Pretensioner Seat-belt with the Active Braking Technology
}

\author{
Qingfeng Feng ${ }^{1}$, Hao $\mathrm{Li}^{2}$, a , Jinhuan Zhang ${ }^{2, \mathrm{~b}}$, Weiguo $\mathrm{Liu}^{1}$, Haiyang Zhang ${ }^{1}$, \\ Ruyang Pan ${ }^{1}$, Honglei Dong ${ }^{3}$, Lingyun $\mathrm{Xiao}^{3, \mathrm{c}, \text { * }}$ \\ ${ }^{1}$ Ningbo Geely Automobile Research and Development Co., Ltd., Hangzhou 311228, China \\ ${ }^{2}$ State Key Laboratory of Automotive Safety and Energy of Tsinghua University, Beijing 100084, \\ China \\ ${ }^{3}$ China National Institute of Standardization, Beijing 100191, China \\ alih7.11@sem.tsinghua.edu.cn, bzhjh@tsinghua.edu.cn, 'xiaoly@cnis.gov.cn
}

Keywords: Active Safety, Passive Safety, Motor Drive, Pretensioner Seat-belt, Safety Protection Strategy.

\begin{abstract}
Active safety and passive safety technology have been developed for many years in foreign countries. According to the studies by some foreign authorities, pre-crash seat-belt can protect the occupant in collision more effectively, and reduce the injury during the accident greatly. In this paper, sled tests and simulation were carried out to analyze the influence of pretensioner on the occupants. It analyzes the important parameters of motor driving belt. It carries out orthogonal experiment, and analysis of the results. From the influential factors, find the optimal combination of parameters. Compared with the simulation and pyrotechnical model, the WIC of optimized model reduces nearly $10 \%$, which improving the safety performance of the seat-belt greatly. Compared with traditional pyrotechnical, the head injury index HIC36 reduces by $16.94 \%$, HIC15 reduces by $20 \%$. Compared with the sled test, the index of the optimal model decreases more than $25 \%$. The effect of active preloaded on the head is more obvious.
\end{abstract}

\section{Introduction}

With increase of car ownership, traffic accidents have become one of the threats to our lives and health, each year more than one million people died in traffic accidents. According to a report published by WHO (World Health Organization) in 2013, about 1.2 million people worldwide died due to traffic accidents and 200-500 million were injured in road traffic accidents ${ }^{[1]}$. Improving the safety of vehicles, reducing damages caused by traffic accidents and lowering the possibility of occupants injures in traffic accidents have been top concerns of the public nowadays ${ }^{[2-3]}$. As a passive safety device, seat belt restraint system in a car is one of the main components of vehicle' s passive safety system, playing an important role in reducing occupants' injuries. In this paper, a study on combining car seat belt preloading device to active safety technology was conducted to better protect the persons in the vehicle ${ }^{[4-6]}$.

This paper is based on the results from experiments. We build a front impact model for a vehicle in MADYMO software, and leverage this model to simulate the real scenarios of a car crash and analyze each scenario. For the full front impact and part impact with different speeds and different forces that applied to the active braking system, the pre-tightening time, speed and force for motor driven pretensioner seat belt are optimized. In addition, the control strategies compatible with active braking technologies and suitable for pre-tensioner seat belt are proposed to enhance the efficiency of restraint system for better protections for the occupants. Specifically, the study covers: verifying the protection of motor driven pre-tensioner seat belt, identifying the typical scenarios of traffic accidents, building simulation models and analyzing the results getting from the simulation models, etc. 


\section{The Testing Platform and Simulation Models for Front Impact}

\subsection{Testing Vehicle Platform}

The testing vehicle contains car seats, a foot pedal and a simulated steering wheel. A Hybrid III 50th male dummy was placed in driver' s seat and posed in driving state with his hands grabbing the steering wheel, before the impact, the vehicle was moving at $40 \mathrm{~km} / \mathrm{h}^{[7]}$. The dummy is seated on the driving seat of the testing vehicle. There is no clearance between dummy' s bottom and seatback. Dummy' s hands are put on the steering wheel with its natural driving pose and his head is adjusted so that the accelerometer for $\mathrm{x}$-axis is leveled horizontally. With all above are well set, the spatial locations for the dummy and testing vehicle are captured by a 3D coordinate measuring instrument. The configurations for the testing vehicle is showed in Fig 1.

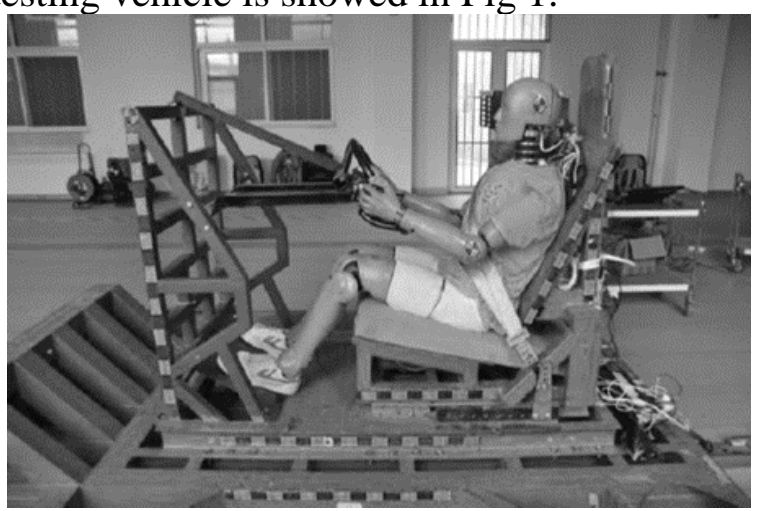

Fig 1. The Testing Vehicle and Its Configurations

\subsection{MADYMO Simulation Models}

According to the geometric parameters of the testing vehicle, a MADYMO simulation model is built, as shown in Fig 2 which includes a steering wheel, foot pedal, seat and seat belt system. Seat belt system model includes a belt retractor, guiding groove, seat height adjuster, D-shaped ring, buckle and anchor plate etc. Based on the relative positions of these components, the webbing pattern of the seat belt and how these components are connected are defined in the model. In building the seat belt model, multi-body dynamics and finite element method are employed, its structure is shown in Fig 3.

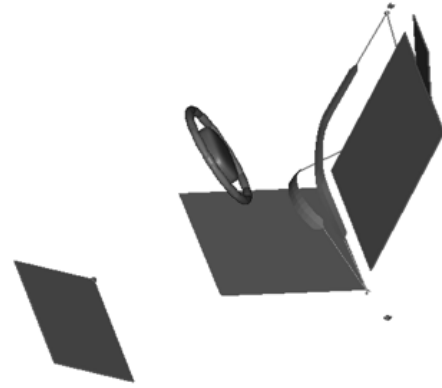

Fig 2. Basic Model of Vehicle Body

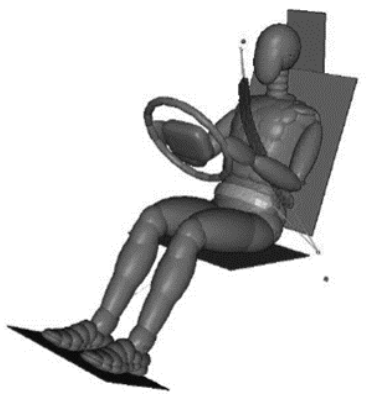

Fig 4. MADYMO Simulation Model

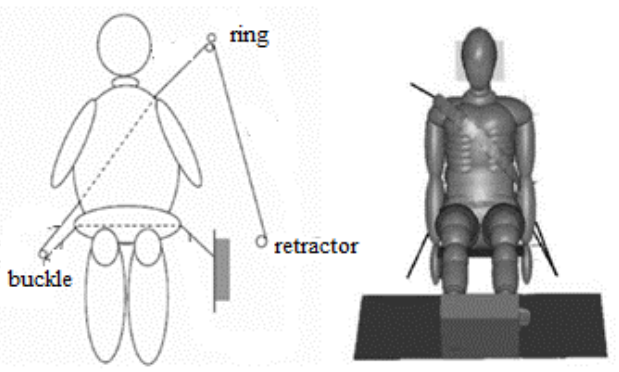

Fig 3. Structure of Seat Belt Model

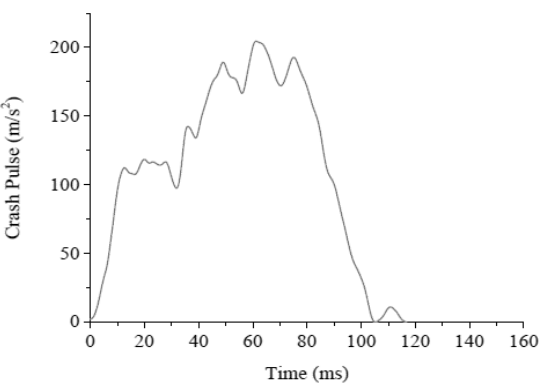

Fig 5. Acceleration Curve Applied to the Vehicle

At last, we got the final model as shown in Fig 4. When a car crash happens, the deformation of cushion in car seats will affect the dummy's respond to the impact. Based on this consideration, the 
cushion in the model is simplified - a curve that reflects the relationship between force and the collapse degree is defined to simulate the deformation of cushion in seat. For the vehicle in the model, a testing wave shown in Fig 5 will be applied to it along the negative direction of $\mathrm{x}$-axis.

\subsection{Benchmarking for Simulation Model}

Comparing the results getting from the vehicle testing and computer simulations, as shown in Table 1. The comparison shows that the damages in the simulation is not much as in the vehicle test. In Fig 6, the dummy's reactions for both vehicle testing and model simulation are shown. Judging from the curves shown in Fig 6, the pulse widths are almost the same. In the vehicle testing, the movement in chest is slightly higher than that in the simulation while no much difference in other curves. As for the head injure curve, there is a latency in simulation results. In Fig 7, the dummy's response at the special moments are shown.

Table 1 Verifying in Simulation Model: Damage Response

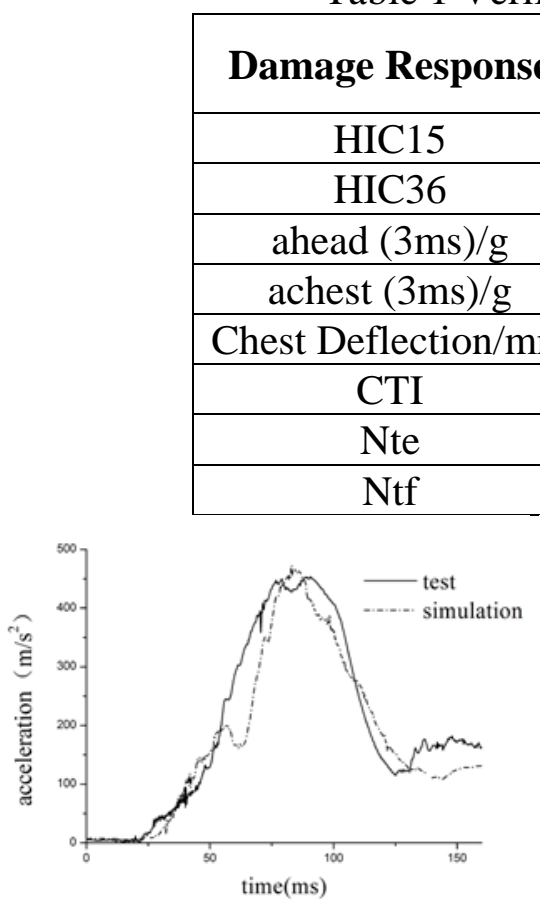

(a) Head

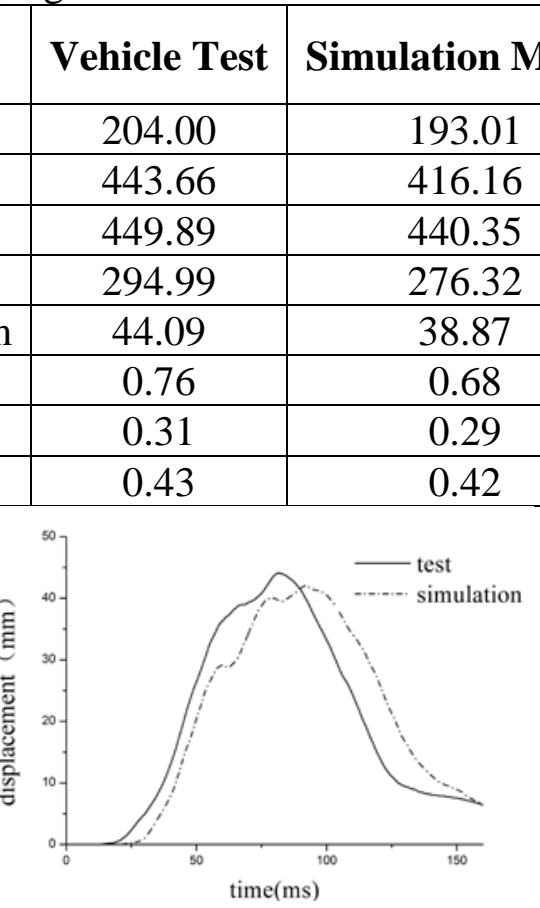

(b) Chest

\begin{tabular}{|c|c|}
\hline $\begin{array}{c}\text { Difference } \\
\text { s }\end{array}$ \\
\hline $5.54 \%$ \\
\hline $6.40 \%$ \\
\hline $2.14 \%$ \\
\hline $6.54 \%$ \\
\hline $12.58 \%$ \\
\hline $11.11 \%$ \\
\hline $6.67 \%$ \\
\hline $2.35 \%$ \\
\hline
\end{tabular}

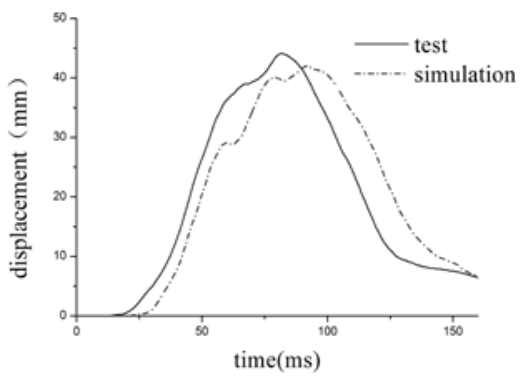

(c) Chest Deflection

Fig 6. Verifying the Benchmarking for Simulation Model: Response Curve to Damages

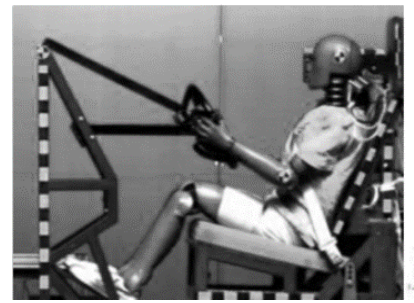

(a) $\mathrm{t}=0 \mathrm{~ms}$

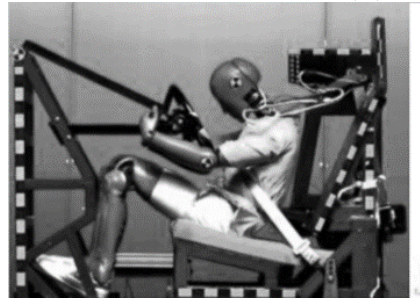

(c) $\mathrm{t}=80 \mathrm{~ms}$
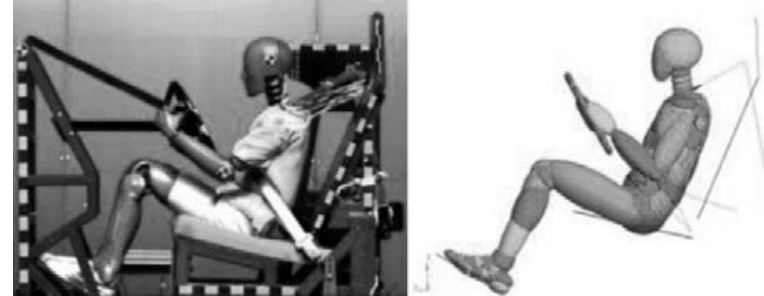

(b) $\mathrm{t}=60 \mathrm{~ms}$

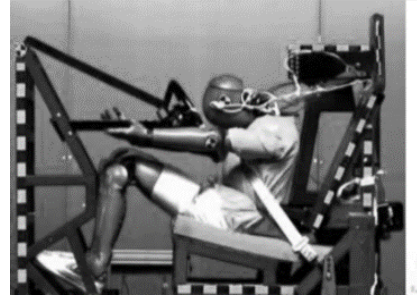

(d) $\mathrm{t}=100 \mathrm{~ms}$

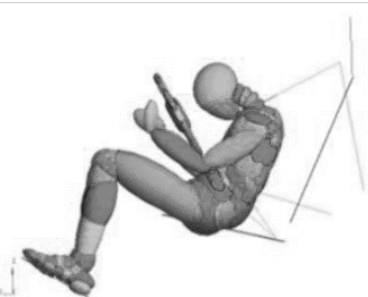

Fig 7. Verifying the Benchmarking for Simulation Model: Dummy's Posture is as in the Movement

In the simulation, the dummy's body movement aligned pretty well with those captured in vehicle testing, just a latency found in dummy's arm movements. This is because dummy's fingers are fixed to the steering wheel by adhesive tapes. To further verify the validity of the simulation model, the 
sitting postures of dummy in vehicle test and simulation are adjusted - a clearance of $25 \mathrm{~mm}$ and $50 \mathrm{~mm}$ respectively between the dummy's back and the seatback are set, as shown in Fig 8, to simulate the scenarios of the real driving where the drivers usually sit in a non-normal posture.

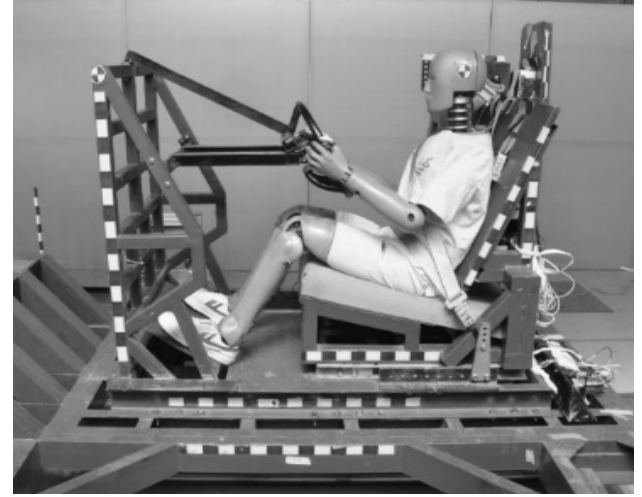

(a) $25 \mathrm{~mm}$

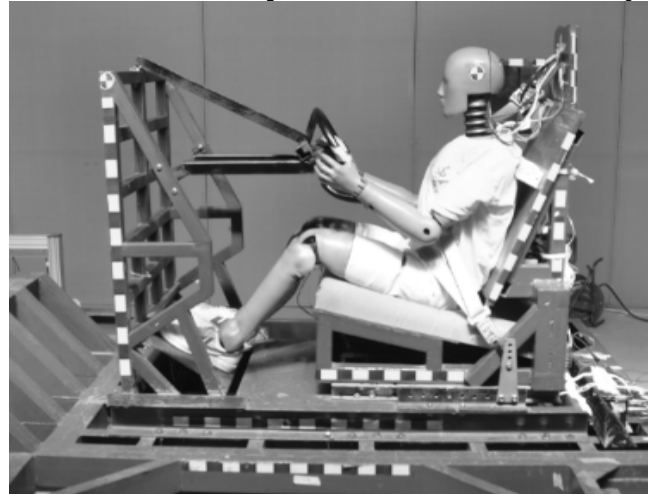

(b) $50 \mathrm{~mm}$

Fig 8. Clearance between Dummy’s Back and Seatback

In both vehicle tests, scenario of $25 \mathrm{~mm}$ clearance is recorded as Scenario 1 while scenario of $50 \mathrm{~mm}$ clearance is recorded as Scenario 2. To verifying Scenario 1, the results of damage response getting from vehicle test and computer simulation are compared in Table 2 and the comparison shows that, the damages in simulation is not much as in vehicle test. To verifying Scenario 2, the results of damage response getting from vehicle test and computer simulation are compared in Table 2 and the comparison shows that, the damages in simulation is not much as in vehicle test, too.

Table 2 Verifying Scenario in Simulation Model: Damage Response

\begin{tabular}{|c|c|c|c|c|}
\hline Verifying Scenario & Damage Response & Vehicle Test & Simulation Model & $\begin{array}{c}\text { Difference } \\
\text { s }\end{array}$ \\
\hline \multirow{4}{*}{1} & HIC15 & 226.60 & 214.66 & $5.41 \%$ \\
\cline { 2 - 5 } & HIC36 & 391.00 & 381.03 & $2.58 \%$ \\
\cline { 2 - 5 } & ahead (3ms)/g & 47.59 & 45.27 & $5.00 \%$ \\
\cline { 2 - 5 } & achest (3ms)/g & 30.58 & 27.60 & $10.24 \%$ \\
\cline { 2 - 5 } & Chest Deflection/mm & 30.58 & 27.60 & $0.70 \%$ \\
\hline \multirow{4}{*}{2} & HIC15 & 226.60 & 191.42 & $7.36 \%$ \\
\cline { 2 - 5 } & HIC36 & 404.44 & 407.50 & $0.75 \%$ \\
\cline { 2 - 5 } & ahead (3ms)/g & 49.94 & 44.90 & $10.62 \%$ \\
\cline { 2 - 5 } & achest (3ms)/g & 30.83 & 27.58 & $11.12 \%$ \\
\cline { 2 - 5 } & Chest Deflection/mm & 36.10 & 35.25 & $2.38 \%$ \\
\hline
\end{tabular}

By comparing the results getting from different scenarios and benchmarking model, we find that the simulation presents a lower value than vehicle tests, means that this is a systematic bias and acceptable. Therefore, we can conclude that the simulation model can reflect the dummy's response in a car crash well.

\section{Verifying the Protection of Pre-tensioner Seat Belt and Optimization of Parameters}

\subsection{Choose Optimized Parameters}

In this part, the protection strategies for motor driven pre-tensioner seat belt are researched. Given the fact that the parameters of pretensioner are closely related with the injures of dummy, pretensioning time, force and the amount of it are chosen as adjustable parameters. Currently, for the existing pyrotechnical pretightening seat belt and reversible pretightening seat belt, the pretightening time is usually restrained between $100 \mathrm{~ms}$ to $500 \mathrm{~ms}$, while the amount of pretightening is set to $80 \mathrm{~mm}$ to $300 \mathrm{~mm}$ and the force of pretightening is controlled in a range of $200 \mathrm{~N}$ to $500 \mathrm{~N}^{[8]}$. In this thesis, Orthogonal Test is employed to verify the design of the simulated model. The range of the parameters used in Orthogonal Test are shown in Table 3 below. 
Table 3 Designs at Parameter Level

\subsection{Optimize Design of Tests}

\begin{tabular}{|c|c|c|c|c|}
\hline & 1 & 2 & 3 & 4 \\
\hline Pretensioning Time A/ms & 100 & 250 & 350 & 500 \\
\hline Amount of Pretightening B/mm & 80 & 150 & 250 & 300 \\
\hline Pretensioning Force C/N & 200 & 300 & 400 & 500 \\
\hline
\end{tabular}

According to the rules of Orthogonal Test, the combined tests are designed, as shown in Table $4{ }^{[9]}$. Table 4 Arrangements for Parameter Tests

\begin{tabular}{|c|c|c|c|c|c|c|c|c|c|c|c|c|c|c|c|c|}
\hline Test No. & 1 & 2 & 3 & 4 & 5 & 6 & 7 & 8 & 9 & 10 & 11 & 12 & 13 & 14 & 15 & 16 \\
\hline A & 1 & 1 & 1 & 1 & 2 & 2 & 2 & 2 & 3 & 3 & 3 & 3 & 4 & 4 & 4 & 4 \\
\hline B & 1 & 2 & 3 & 4 & 1 & 2 & 3 & 4 & 1 & 2 & 3 & 4 & 1 & 2 & 3 & 4 \\
\hline C & 1 & 2 & 3 & 4 & 2 & 1 & 4 & 3 & 3 & 4 & 1 & 2 & 4 & 3 & 2 & 1 \\
\hline
\end{tabular}

\subsection{Optimizations}

In this thesis, WIC is chosen as the indicator to evaluate how serious the occupant is injured ${ }^{[10]}$. WIC features with wide assessment range. In WIC evaluation, injures in different part of the body will be weighted differently, which has been proved to be of great value in identifying the degrees of personal injuries. The formula for calculating WIC is:

$$
W I C=0.6\left(\frac{H I C_{36}}{1000}\right)+0.35\left(\frac{C_{3 m s}}{60}+\frac{C_{\text {comp }}}{0.076}\right) / 2+0.05\left(F_{L}^{\text {femur }}+F_{R}^{\text {femur }}\right) / 20
$$

Where, HIC36 is 36 integral value for head injury criterion; C3ms means standard acceleration at chest for 3ms, measured in g (acceleration of gravity, $1 \mathrm{~g}=9.80 \mathrm{~m} / \mathrm{s}^{2}$ ), Ccomp is compression in chest, measured in m, FLfemur and FRfemur are maximum axial forces born by left leg and right leg respectively, measured in $\mathrm{KN}$. In this formula, the value in each denominator is the threshold of such injury criterion. Therefore, in the calculation that follows, HIC is calculated as per FMVSS-208 Code, and the integral value for head injury criterion is specified as $15 \mathrm{~ms}$ with a threshold of 700 .

As arranged in Table 5, tests are run and following results are gained and shown in Table 5.

Table 5 Results from Simulated Injury

\begin{tabular}{|c|c|c|c|c|c|c|}
\hline Tests No. & HIC & C3ms (g) & $\begin{array}{c}\text { Ccom(mm } \\
\text { ) }\end{array}$ & FFCL (kN) & FFCR(kN) & WIC \\
\hline 1 & 178.08 & 32.278 & 43.402 & 0.142 & 0.129 & 0.3474 \\
\hline 2 & 205.08 & 32.044 & 43.735 & 0.135 & 0.116 & 0.3712 \\
\hline 3 & 220.27 & 31.571 & 43.153 & 0.114 & 0.095 & 0.3807 \\
\hline 4 & 231.75 & 32.051 & 42.543 & 0.085 & 0.075 & 0.3904 \\
\hline 5 & 200.44 & 31.320 & 42.836 & 0.146 & 0.122 & 0.3624 \\
\hline 6 & 187.27 & 31.989 & 43.123 & 0.157 & 0.136 & 0.3538 \\
\hline 7 & 289.15 & 31.257 & 41.068 & 0.085 & 0.099 & 0.4340 \\
\hline 8 & 276.22 & 31.929 & 42.808 & 0.085 & 0.110 & 0.4289 \\
\hline 9 & 188.45 & 31.302 & 42.151 & 0.110 & 0.094 & 0.3503 \\
\hline 10 & 188.69 & 31.382 & 42.123 & 0.101 & 0.081 & 0.3507 \\
\hline 11 & 188.00 & 32.032 & 42.875 & 0.152 & 0.134 & 0.3540 \\
\hline 12 & 205.97 & 31.447 & 43.209 & 0.150 & 0.127 & 0.3684 \\
\hline 13 & 208.72 & 31.348 & 39.797 & 0.075 & 0.085 & 0.3623 \\
\hline 14 & 216.44 & 31.47 & 39.829 & 0.088 & 0.088 & 0.3694 \\
\hline 15 & 232.73 & 32.651 & 39.069 & 0.093 & 0.100 & 0.3851 \\
\hline 16 & 213.76 & 32.46 & 40.521 & 0.131 & 0.115 & 0.3718 \\
\hline
\end{tabular}

Range method is the most wildly used method for analyzing the results from Orthogonal Test. In this method, each factor that affects the test will be computed to identify its influence, and then the best parameters for such factor will be chosen to achieve a fully optimized combination ${ }^{[11]}$. 
$\mathrm{Rm}$ is the Rang of factors in Column M, e.g. when specified with different values, the difference between maximum and minimum for each factor.

$$
R_{m}=\max \left(\overline{\mathrm{K}_{\mathrm{m} 1}}, \overline{\mathrm{K}_{\mathrm{m} 2}}, \ldots, \overline{\mathrm{K}_{\mathrm{mn}}}\right)-\min \left(\overline{\mathrm{K}_{\mathrm{m} 1}}, \overline{\mathrm{K}_{\mathrm{m} 2}}, \ldots, \overline{\mathrm{K}_{\mathrm{mn}}}\right)
$$

$\mathrm{Rm}$ reflects the changes of factors in Column M, e.g. the variation range for the tested factor. The greater Rmis, the more influence this factor will be, in another word, the more important it will be. Thus, the importance of each factor can be identified according to the value of $\mathrm{Rm}^{[12-14]}$.

In this thesis, WIC is chosen as the tested factor, Range method is leveraged and the results are gained and shown in Table 6.

Table 6 Data Processed Results

\begin{tabular}{|c|c|c|c|c|}
\hline & A & $\mathrm{B}$ & $\mathrm{C}$ & Remark \\
\hline K1 & 1.4897 & 1.4224 & 1.4270 & \multirow{8}{*}{$\begin{array}{c}\text { Weighted Injury Criterion (WIC) } \\
\text { and Average Value }\end{array}$} \\
\hline $\mathrm{K} 2$ & 1.5791 & 1.4451 & 1.4871 & \\
\hline K3 & 1.4234 & 1.5538 & 1.5293 & \\
\hline K4 & 1.4886 & 1.5595 & 1.5374 & \\
\hline K1Average & 0.3724 & 0.3556 & 0.3568 & \\
\hline K2Average & 0.3948 & 0.3613 & 0.3718 & \\
\hline K3Average & 0.3559 & 0.3885 & 0.3823 & \\
\hline K4Average & 0.3722 & 0.3899 & 0.3844 & \\
\hline R (Range) & 0.0389 & 0.0343 & 0.0276 & The Value for Averaged Range \\
\hline Optimum & 3 & 1 & 1 & \\
\hline
\end{tabular}

Judging from the results of Range Method shown in Table 7, we can conclude that the best combination is A3B1C1, which was not presented in original simulation. We run a simulating computing for this combination, the optimal indicators for occupant's injury are achieved and the used simulation model is used to simulate the operation of traditional pyrotechnic pretensioner seat belt. The simulated results is compared in Fig 9.

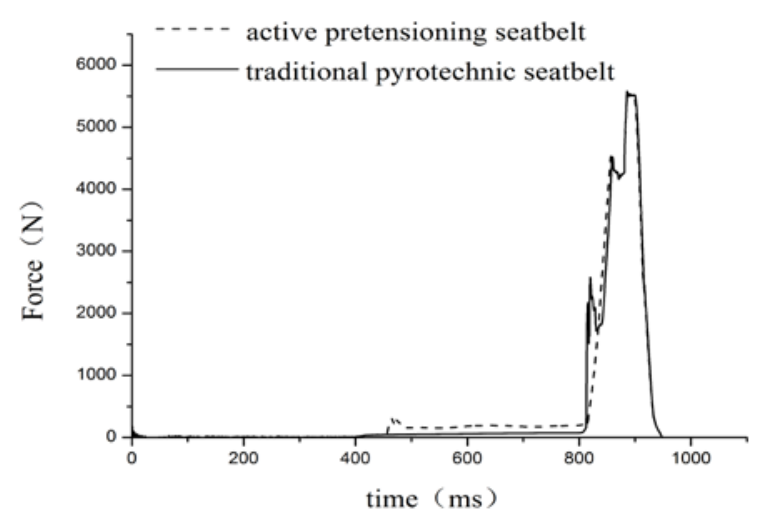

(a) Restraint Force of Shoulder Harness in Seat Belt

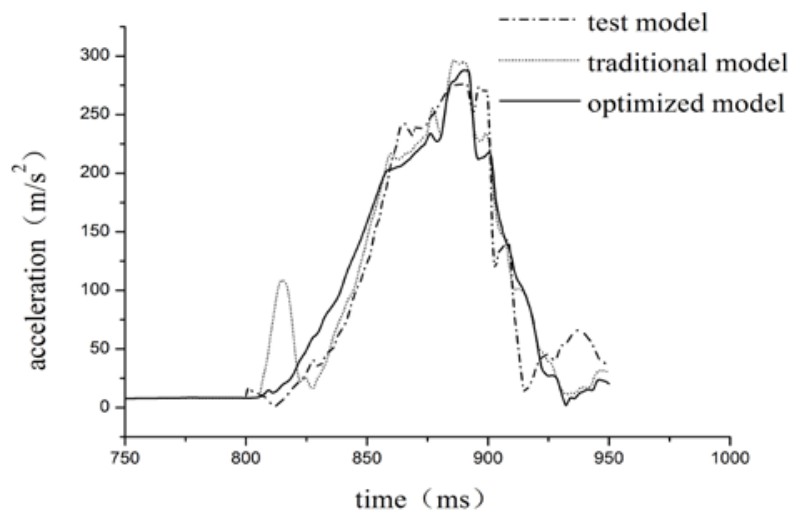

(c) Chest Acceleration

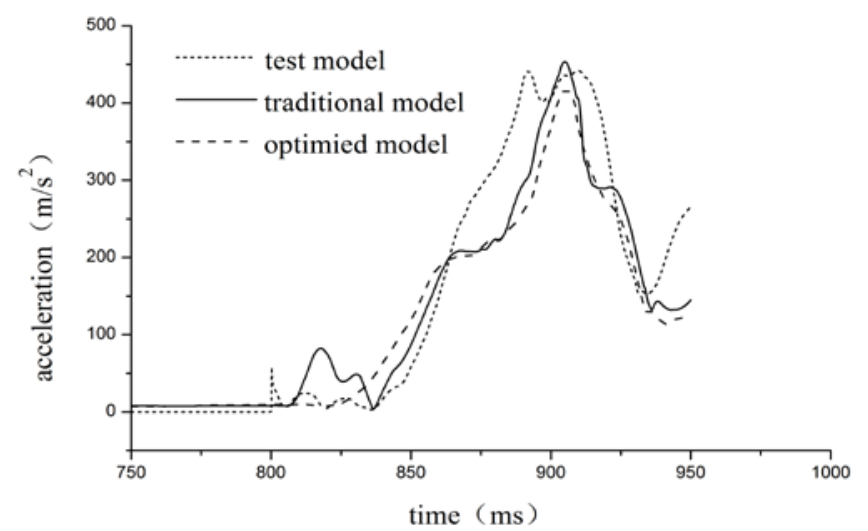

(b) Head Acceleration

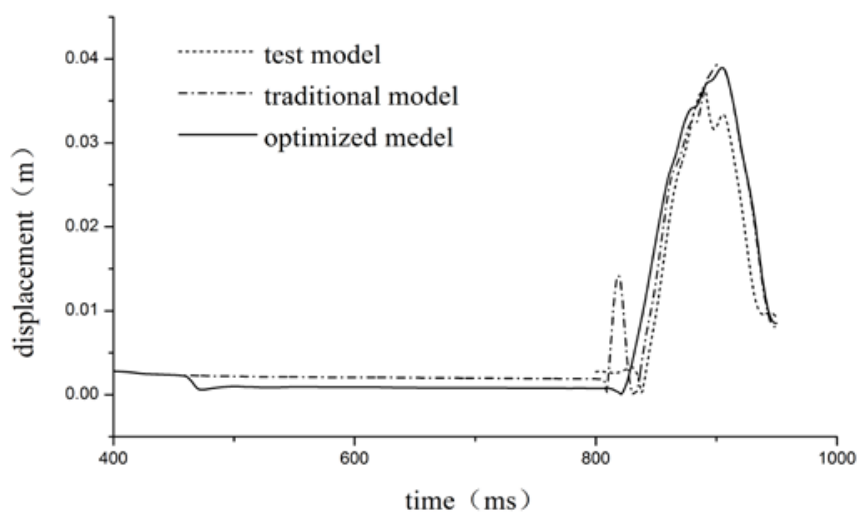

(d) Chest Deflection

Fig 9. Comparison Curves for Each Indicator 
Fig 9 (a) recorded the change of shoulder harness force in two different pretensioning ways. The braking mechanism begins to work at $800 \mathrm{~ms}$ before the impact; at $350 \mathrm{~ms}$ before the impact, active pretensioner seat belt begin to work and the force on shoulder harness begins to accumulate and reach to peak value of $200 \mathrm{~N}$, providing protections to the driver until the impact happens at $800 \mathrm{~ms}$, at that very moment, the force on shoulder harness increases immediately and reaches to about 2000N. Due to the presence of load limiter, which is set to Class I Limitation, both these two pre-tesioning forces are dropped a little at the peak value of $4000 \mathrm{~N}$. With the forces on shoulder harness increase to similar peak value of $5500 \mathrm{~N}$, they will drop again. Fig 9 (b), (c), and (d) show the comparison of injury indicators in head and chest, we can see that, compared with traditional pretensioner seat belt, the injury indicators for active pretensioner seat belt are lower, meaning this kind of pretensioner seat belt can provide better protection to the occupants; judging from the curves of head acceleration and chest acceleration, the dummy with pretensioner seat belt buckled experienced a shorter accelerating process, which means pretensioner seat belt can provide better protection to the occupants ${ }^{[15]}$.

The optimized model, benchmarking model for vehicle simulation and their comparison to traditional pyrotechnic pretensioner seat belt are shown in Table 7.

Table 7 Comparison of Injury Indicators Pre/Post Optimization

\begin{tabular}{|c|c|c|c|c|c|c|c|}
\hline Category & НIC36 & HIC15 & $\begin{array}{c}\text { C3ms } \\
\text { (g) }\end{array}$ & Ccomp $(\mathrm{mm}$ & FFCL(KN) & FFCR(KN) & WIC \\
\hline Standard & $\leq 1000$ & $\leq 700$ & $\leq 60$ & $\leq 76$ & $\leq 10$ & $\leq 10$ & $\leq 1.0$ \\
\hline $\begin{array}{l}\text { Benchmarking } \\
\text { Model for Vehicle } \\
\text { Simulation }\end{array}$ & 416.16 & 193.01 & 28.17 & 36.13 & 0.18 & 0.16 & 0.33 \\
\hline $\begin{array}{l}\text { Model for } \\
\text { Traditional } \\
\text { Pyrotechnic } \\
\text { Pretensioner }\end{array}$ & 276.67 & 177.20 & 30.01 & 38.89 & 0.18 & 0.17 & 0.32 \\
\hline $\begin{array}{c}\text { Model for the Best } \\
\text { Active } \\
\text { Pretensioner }\end{array}$ & 229.81 & 144.03 & 29.24 & 38.42 & 0.15 & 0.13 & 0.29 \\
\hline $\begin{array}{l}\text { Improvement with } \\
\text { Optimization } \\
\text { Compared to } \\
\text { Benchmarking } \\
\text { Model }\end{array}$ & $44.78 \%$ & $25.3 \%$ & $-3.8 \%$ & $-6.4 \%$ & $17.9 \%$ & $18.5 \%$ & $10.2 \%$ \\
\hline $\begin{array}{l}\text { Improvement with } \\
\text { Optimization } \\
\text { Compared to } \\
\text { Traditional Medel }\end{array}$ & $16.94 \%$ & $18.7 \%$ & $2.5 \%$ & $1.1 \%$ & $18.3 \%$ & $24.5 \%$ & $9.4 \%$ \\
\hline
\end{tabular}

In optimized model, active pretensioner is added and the pretensioning time is shortened compared with traditional pyrotechnic pretensioner, thus the amount of pretensioning, as well, the force of pretensioning are all optimized. From the comparison, we can know that, in the model for the best active pretensioner, WIC decreases $10 \%$ in average, providing a better protection for the occupants. Compared to traditional pyrotechnic pretensioner, the head injury criterion HIC36decreases 16.94\%; HIC15 decreases 20\%; compared to the benchmarking model of vehicle, the HIC decreases more than $25 \%$ that we can conclude that, active pretensioner will provide a better protection to occupants' heads.

\section{Conclusion}

Being verified by the vehicle tests and corresponding simulation computing, the following conclusions can be drawn from the study conducted in this thesis. 1) Compared with seat belt without pretensioner, the dummy with pretensioner seat belt buckled in experienced a softer acceleration 
process in which the peak acceleration lasts a short time in head and chest, means that the pretensioner seat belt can provide a sound protection to the occupants. 2) Compared with seat belt that employed traditional pretensioner, the active pretensioner seat belt presents a relative lower injury indicators. 3) WIC for the optimized model of active pretensioner seat belt decreases $10 \%$ on average means this kind of equipment can improve the protections for the occupants. 4) Compared to traditional pyrotechnic pretensioner, the head injury criterion HIC36 decreases 16.94\%; HIC15 decreases 20\%; compared to the benchmarking model of vehicle, the HIC decreases more than 25\%.

\section{Acknowledgments}

This work is supported in part by National Key Technology Research and Development Program of the Ministry of Science and Technology of China (2014BAK01B05) and in part by the National Fund for Fundamental Research (No. 282015Y-4005).

\section{References}

[1] Pedennm.et al. World Report on Road Traffic Injury Prevention. Geneva: Word Health Organization, 2014:1-5.

[2] Treat J R Tumbas N S, Mcdonald S T. Tri-level study of the causes of traffic accidents [R]. Ann Arbor: Transport Research Institute, 1979.

[3] Vollrath.M, Briest.S, Schie. Ableitung.von. Anforderungen.an. Fahrerassistenz systeme aus Sicht der Verkehrssicherheit [R].Bergisch Gladbach: BAST, 2006.

[4] Jurgen Debold. Active Safety Systems-The Home for Global Chassis Control. SAE paper, No.2006-21-0079

[5] P. D. Bois, C. C. Chou, B. B. Fileta, et al., Vehicle Crashworthiness and Occupant Protection, Southfield, Michigan: AISI, 2000, pp.271 279.

[6] W. Reidelbach, H. Scholz, Advanced Restraint System Concepts, SAE Technical Paper, 790321, 1979.

[7] D.C. Viano, Limits and Challenges of Crash Protection, Accid. Anal. \& Prev., vol. 20, no. 6, pp. 421-429, Dec. 1988.

[8] D.C. Viano, C.S. Parenteau, R. Burnett, " Influence of Belt Pretensioning on Dummy Responses in 40 km/h Rear-impact Sled Tests," Traffic Inj. Prev. vol. 13, no. 1, pp. 65-71, 2012.

[9] P. Ruecker, Crash Tests with Automatic Pre-Crash Braking Cars, SAE Technical Paper, 2013-01-0200, 2013.

[10] X. Luo, W. J. Du, J. H. Zhang, Safety Benefits of Motorized Seat Belt as a Component in ADAS in Front-end Collisions, IEEE Conf. on Intelligent Transportation Systems, Qingdao, China, 2014, pp.661-666.

[11] R Schoneburg, T Breitling. Enhancement of Active and Passive Safety by Future PRE-SAFE® Systems, 2005 ESV Conference, Washington DC, USA, Paper 05-0080

[12] Hideo Tobata, Chinmoy Pal, Hideo Takagi. Development of a Brake-Operated Pre-Crash Seatbelt System and Performance Evaluation. 2004 SAE World Congress

[13] Mark Mages, Martin Seyffert, Uwe Class. Analysis of the Pre-Crash Benefit of Reversible Belt Pre-Pretensioning in Different Accident Scenarios. 22th ESV Conference.

[14] LUO Xiao, YAO Yuan, ZHANG Jinhuan. Unified calibration method for millimeter-wave radar and camera. J Tsinghua Univ (Sci and Tech), 2014.54(3), 289-293. (In Chinese)

[15] LUO Xiao, YAO Yuan, LI Peiyu, et al. Vehicle Width and Position Measurement Method for Pre-crash System. J Automotive Engineering, 2016.38(2), 181-184. (In Chinese) 